\title{
Cost-effectiveness of palivizumab in infants with congenital heart disease: a Swedish perspective
}

\author{
Eva Fernlund ${ }^{1}$, Martin Eriksson ${ }^{2}$, Jonas Söderholm², ${ }^{2,}$ Jan Sunnegårdh ${ }^{4}$ and Estelle Naumburg ${ }^{5^{*}}$ (D)
}

\begin{abstract}
Background: Infants with congenital heart disease (CHD) have an increased risk of morbidity and mortality during a respiratory syncytial virus (RSV) infection. The aim of this study was to estimate the cost-effectiveness of palivizumab as RSV-prophylaxis among infants with CHD, including the effect of delayed heart surgery and asthma.

Methods: A simulation model with data from the literature and health care authorities including costs and utilities was developed to estimate costs and health effects over a lifetime for a cohort of CHD infants receiving palivizumab compared to no RSV-prophylaxis.

Results: The prophylaxis treatment incurred a cost of 3664 EUR per treated infant. However, due to cost-savings from primarily avoiding hospitalizations (5145 EUR/treated infant) and avoiding heart complications due to delayed heart surgery (2082 EUR/treated infant), the RSV-prophylaxis treatment resulted in a total cost-saving of 3833 EUR per treated infant. At the same time, the prophylaxis-treated cohort accumulated more life-years and higher quality of life than the non-prophylaxis cohort.
\end{abstract}

Conclusion: This study confirms that RSV-prophylaxis in severe CHD infants less than one year of age is cost beneficial. Avoiding delayed heart surgeries is an important benefit of prophylaxis and should be taken into consideration.

Keywords: Congenital heart defect, Cost-effectiveness analyses, Palivizumab, Prophylaxis, RSV-infection

\section{Background}

Respiratory syncytial virus (RSV) is the leading cause of lower respiratory tract infections (LRTI) in infants and young children. Severe RSV may result in acute respiratory failure and hospitalization with supplemental oxygen, mechanical ventilation, and intensive care (ICU), especially for infants and children at risk [1, 2]. Infants with congenital heart disease (CHD) carry a risk of morbidity and mortality from RSV infection worldwide as well as in Scandinavia [3, 4]. Long-term sequelae from RSV-infections are wheezing and asthma [5-8].

\footnotetext{
* Correspondence: estelle.Naumburg@umu.se

${ }^{5}$ Department of Clinical Science, Paediatrics, Umeå University, Umeå, Sweden Full list of author information is available at the end of the article
}

Cardiac surgery performed during an ongoing RSV infection is associated with a high risk of postoperative complications, prolonged postoperative stay at the pediatric intensive care unit (PICU), and morbidity [911]. Postponing cardiac surgery is thus appropriate in infants with symptomatic viral respiratory infection. However, postponing will, on the other hand, increase the risk of morbidity and mortality induced by the cardiac disease.

Palivizumab (Synagis ${ }^{\circ}$, MedImmune) is a monoclonal antibody designed to provide passive immunity against RSV - thereby reducing the severity of RSV infection in infants at high risk, including infants with CHD [12-14].

(c) The Author(s). 2020 Open Access This article is licensed under a Creative Commons Attribution 4.0 International License, which permits use, sharing, adaptation, distribution and reproduction in any medium or format, as long as you give appropriate credit to the original author(s) and the source, provide a link to the Creative Commons licence, and indicate if changes were made. The images or other third party material in this article are included in the article's Creative Commons licence, unless indicated otherwise in a credit line to the material. If material is not included in the article's Creative Commons licence and your intended use is not permitted by statutory regulation or exceeds the permitted use, you will need to obtain permission directly from the copyright holder. To view a copy of this licence, visit http://creativecommons.org/licenses/by/4.0/ The Creative Commons Public Domain Dedication waiver (http://creativecommons.org/publicdomain/zero/1.0/) applies to the data made available in this article, unless otherwise stated in a credit line to the data. 
Cost-effectiveness analyses of palivizumab in infants and children with CHD have previously been done, where most studies compared palivizumab prophylaxis to no prophylaxis with the results suggesting cost effectiveness [15-19]. Most studies were performed in highincome countries and only one in Scandinavia for over 16 years ago [20]. Significant variance exist across these study characteristics such as age of the included children, duration of assessed RSV seasons, primary outcome measures evaluated, sensitivity analyses conducted, and other model assumptions [21].

The aim of the present study was to estimate the costeffectiveness of palivizumab as RSV-prophylaxis according to national guidelines among Swedish infants with $\mathrm{CHD}$, including delayed heart surgery, risk of asthma, and costs related to parental care (Additional file 1).

\section{Methods}

This analysis was based on a Markov model [22, 23] with annual cycles comparing the cost-effectiveness of palivizumab as RSV-prophylaxis to no prophylaxis for Swedish infants with CHD. The simulated population was treated with RSV-prophylaxis to infants aged up to one year with hemodynamic significant $\mathrm{CHD}$ and subject to the national Swedish prophylactic program for palivizumab [24]. The analysis was performed from a societal perspective with a lifetime time-horizon and quality-adjusted life-years (QALYs) as the health outcome. Results are expressed in incremental costeffectiveness ratios (ICER; euros [EUR]/QALY). Costs and effects were discounted at $3 \%$ annually as per the Swedish Dental and Pharmaceutical Benefits Agency (Tandvårds- och Läkemedelsförmansverket, TLV) guidelines [25]. All costs in this study were calculated in Swedish krona (SEK) based on the health-care pricelevel of 2019 and expressed in EUR in year 2019 values $(1 \mathrm{EUR}=10.5892$ SEK $)$.

\section{Model structure}

The health states and possible transitions of the Markov model are shown in Fig. 1. The model structure was similar to the structure used in previously published cost-effectiveness analyses of RSV-prophylaxis [16, 23], but with the addition of possible complications from

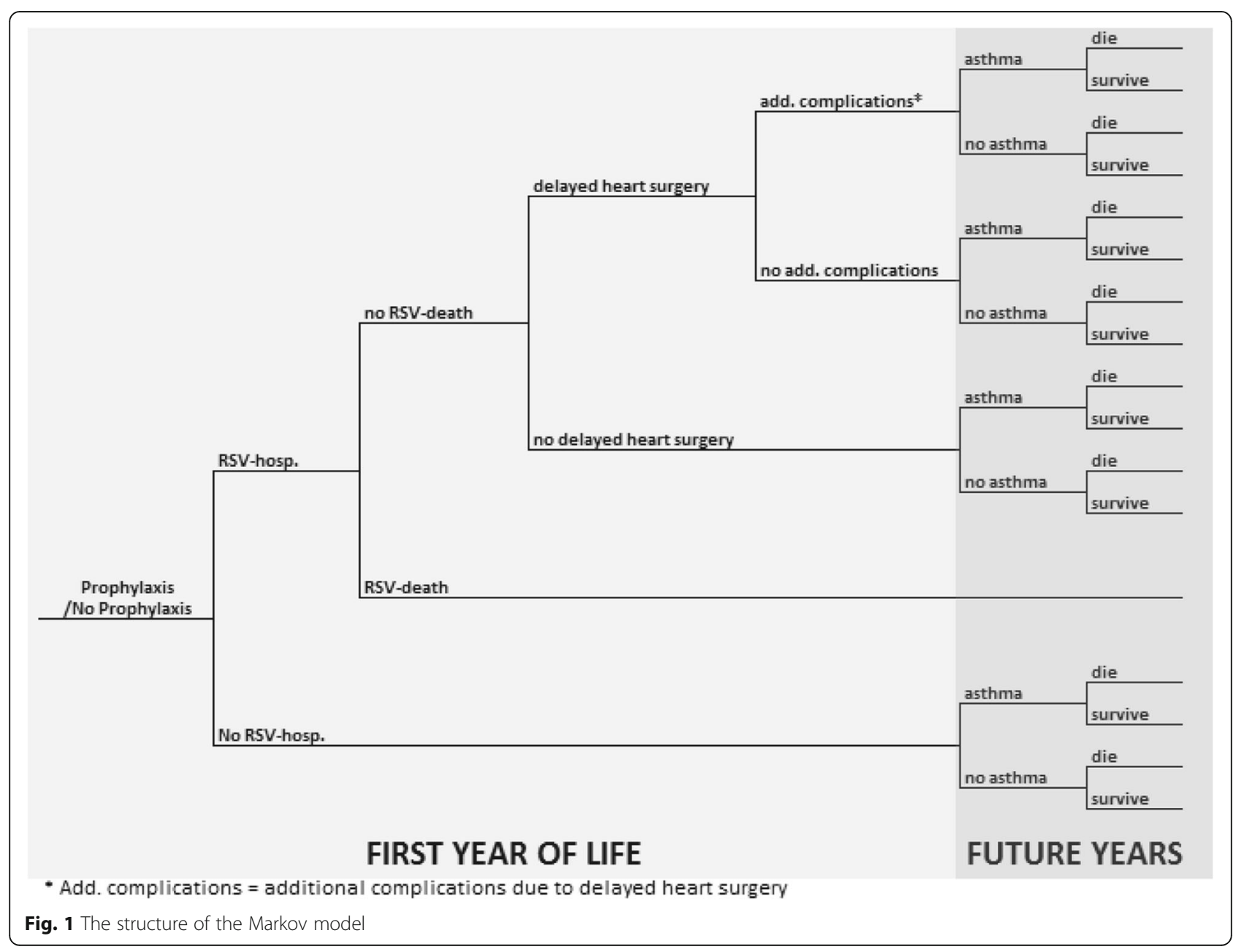


delayed heart surgery, costs due to parental care and risk of asthma. The simulation was started during the first year of life for a cohort of Swedish infants with CHD subject to RSV-prophylaxis according to national guidelines [24]. At the start of the RSV-season, a proportion of these infants would be infected with RSV leading to RSV-hospitalization, and in some cases even death. RSVhospitalization was modeled to delay the planned heart surgery in an estimated number of cases affected by RSV during the winter season, where the risk of CHDassociated complications, including death, would rise. During the future years of simulation, the infants were subjected to a risk of asthma - with a higher risk for those with a history of RSV-hospitalization. The prevalence of the CHD-associated complications was unchanged from the first year. Mortality risks were identical for all children with CHD after the first year. For the RSV-prophylaxis cohort, palivizumab was modeled to be administered only during the RSV season of the first year of simulation.

\section{Risk data and treatment effects of palivizumab}

For the palivizumab-treated cohort the following direct treatment effects were modeled based on the randomized clinical trial on palivizumab in CHD infants [13]:

- Lower risk of RSV-hospitalization

- Less severe RSV-infection if hospitalized

Data related to RSV-infection and hospitalization, continuous positive airway pressure (CPAP), extracorporeal membrane oxygenation (ECMO) and RSV-related death, as well as asthma following RSV, have been retrieved from well-known studies [7, 13, 26-31]; hospital economists at one of the hospitals (Linköping) were consulted when data was not available (Table 1). After 18 years of age, no further difference in the prevalence of asthma was assumed in the present analysis.

The risk of death has been estimated to a hazard ratio (HR) of 64 for the group of children born during the 1990's with the most severe defects and would be included in the national prophylactic program of palivizumab [40]. Survival rates have improved among children born as of 2010, and the survival rates are thus expected to improve to approximately $80 \%[41,42]$.

The risk of delayed heart surgery due to RSVhospitalization was $30 \%$, based on information from a Swedish study from 2014 on adherence to guidelines of palivizumab - where $30 \%$ of children with prophylactic treatment had their operation delayed [43]. Among infants with delayed heart surgery, around $40 \%$ were estimated to have heart complications (expert opinion within the group).

\section{Cost data}

\section{Cost of palivizumab}

The cost of palivizumab was based on five injections with a dose of $15 \mathrm{mg} / \mathrm{kg}$ at a cost of 8.25 EUR per mg (Table 1). We assumed that some children were born late during season and therefore not in need of all five doses, but some were older at start of season and outgrew the national guidelines recommended age during season. Thus, we assumed for the calculations that the overall number of children during a season and we accounted for five doses during the season.

Data on weight of infants were retrieved from 30 patients with severe CHD receiving RSV-prophylaxis according to national guidelines at Linköping Children's Hospital. In this dataset, the mean weights at dose $1,2,3,4$, and 5 of palivizumab were $5.0 \mathrm{~kg}, 5.4$ $\mathrm{kg}, 5.8 \mathrm{~kg}, 6.4 \mathrm{~kg}$ and $7.0 \mathrm{~kg}$, respectively. The resulting cost of RSV-prophylaxis per infant and season was 3664 EUR (Table 1).

\section{Cost of RSV-hospitalization}

Data on cost of hospitalization, supplementary oxygen, mechanical ventilation, CPAP, and ECMO are presented in Table 1. In Sweden, parents are provided parental allowance if the child is hospitalized. The cost for the society for this was estimated to be 118 EUR per day based on data from Statistics Sweden [35]. Mean length of hospitalization (10.8 days with prophylaxis vs. 13.3 days without prophylaxis) and ICU days (3.0 days with prophylaxis vs. 7.3 days without prophylaxis) were calculated based on Feltes et al. [13]. The resulting total costs per RSV-hospitalization, when combined with the length of stay data, was 96,918 EUR for prophylaxis treated infants and 106,344 EUR for non-treated infants (Table 1).

\section{Cost of CHD-associated complications following postponed operation and RSV-sequalae as asthma}

The costs of a general CHD-associated complication following delayed heart surgery was calculated as the value of $100 \%$ productivity loss, assuming that one parent would initially need to be at home full-time with the infant, and that all the individuals with these heart complications do not enter the labor market as adults. The resulting annual cost of a general CHD-associated complication using these assumptions was 21,506 EUR (Table 1). The annual cost of asthma per infant has been gathered from estimations [23] building on studies on adults [44] and preschool children [45].

\section{Utility data}

The utility of the modeled CHD-infants was assumed to be equal to the utility of premature infants as previously described by Greenough et al. [37]. The base utility was accordingly set to 0.89 for all infants, with a decrement 
Table 1 Input data used in the model

\begin{tabular}{|c|c|c|c|}
\hline & \multicolumn{2}{|l|}{ Cohort } & \multirow[b]{2}{*}{ Source } \\
\hline & RSV-prophylaxis & No Prophylaxis & \\
\hline \multicolumn{4}{|l|}{ Palivizumab as RSV-prophylaxis } \\
\hline Dose & 15 mg/kg & & \\
\hline Price & 8.25 EUR/mg & & \\
\hline \multicolumn{4}{|l|}{ Weight (cost per injection): } \\
\hline 1st injection & $5 \mathrm{~kg}$ (619 EUR) & & \\
\hline 2nd injection & $5.4 \mathrm{~kg}$ (668 EUR) & & \\
\hline 3rd injection & $5.8 \mathrm{~kg}$ (718 EUR) & & \\
\hline 4th injection & 6.4 kg (792 EUR) & & \\
\hline 5th injection & $7 \mathrm{~kg}(866$ EUR) & & \\
\hline Total prophylaxis costs per treated infant: & 3664 EUR & & \\
\hline \multicolumn{4}{|l|}{ RSV-hospitalization } \\
\hline Annual risk of RSV-hospitalization (1st year of life) & $5.34 \%(R R=0.55)$ & $9.70 \%$ & Feltes et al. [13] \\
\hline Risk of death during RSV-hospitalization & $3.72 \%$ & $3.72 \%$ & Feltes et al. [13] \\
\hline Mean length of stay, RSV-hospitalization & 10.8 days & 13.3 days & Feltes et al. [13] \\
\hline Mean length of stay, ICU & 3.0 days & 7.3 days & Feltes et al. [13] \\
\hline \multicolumn{4}{|l|}{ Mean length of... } \\
\hline supplemental oxygen & 5.2 days & 10.4 days & Feltes et al. [13] \\
\hline mechanical ventilation & 1.2 days & 5.6 days & Feltes et al. [13] \\
\hline ECMO & 8.2 days & 8.2 days & Khan et al. [27] \\
\hline CPAP & 3.5 days & 3.5 days & Greenough et al. [32] \\
\hline \multicolumn{4}{|l|}{ Cost per day } \\
\hline RSV-hospitalization & 1197 EUR & 1197 EUR & SSVR County Council Price List [33] \\
\hline ICU & 1802 EUR & 1802 EUR & SSVR County Council Price List ${ }^{1}[33]$ \\
\hline Supplemental oxygen & 344 EUR & 344 EUR & SÖSVR County Council Price List [34] \\
\hline Mechanical ventilation & 344 EUR & 344 EUR & SÖSVR County Council Price List [34] \\
\hline ECMO & 8592 EUR & 8592 EUR & SSVR County Council Price List [33] \\
\hline CPAP & 3338 EUR & 3338 EUR & SÖSVR County Council Price List ${ }^{a}$ [34] \\
\hline Hotel (1 parent) & 96 EUR & 96 EUR & SSVR County Council Price List [33] \\
\hline Productivity loss (1 parent) & 118 EUR & 118 EUR & Statistics Sweden [35] \\
\hline Resulting total costs per RSV-hospitalization & 96,918 EUR & 106,344 EUR & \\
\hline \multicolumn{4}{|l|}{ CHD-associated complications } \\
\hline Risk of delayed surgery, if RSV-hospitalized & $30 \%$ & $30 \%$ & Granbom et al. [36] \\
\hline \multicolumn{4}{|l|}{ For infants with delayed surgery: Risk of . } \\
\hline general complication & $40 \%$ & $40 \%$ & Assumed \\
\hline death (during first year) & $1 \%$ & $1 \%$ & Assumed \\
\hline Annual cost of general heart complication & 21,506 EUR & 21,506 EUR & Assumed \\
\hline \multicolumn{4}{|l|}{ Asthma } \\
\hline Annual risk of asthma & \multicolumn{2}{|c|}{ (Depending on age and history of RSV-hospitalization) } & Sigurs et al. $[7,28,29]$ \\
\hline Annual cost of asthma & 1440 EUR & 1440 EUR & Neovious et al. [23] \\
\hline \multicolumn{4}{|l|}{ Utilities } \\
\hline Base utility & 0.89 & 0.89 & Greenough et al. [37] \\
\hline Utility decrement of RSV hospitalization & 0.10 & 0.10 & Assumed \\
\hline Utility of asthma & 0.79 & 0.79 & Chiou et al. [38] \\
\hline
\end{tabular}


Table 1 Input data used in the model (Continued)

\begin{tabular}{llll}
\hline & \multicolumn{2}{l}{ Cohort } & \\
\cline { 2 - 3 } & RSV-prophylaxis & No Prophylaxis & Source \\
\hline Utility decrement of heart complication & 0.10 & 0.10 & Assumed \\
$\begin{array}{l}\text { Discount rates } \\
\text { Costs (annual) }\end{array}$ & $3.0 \%$ & $3.0 \%$ & TLV guidelines [39] \\
QALYs (annual) & $3.0 \%$ & $3.0 \%$ & TLV guidelines [39] \\
\hline
\end{tabular}

CPAP Continuous positive airway pressure, ECMO Extracorporeal membrane oxygenation, ICER incremental cost-effectiveness ratio, ICU Intensive care unit, Proph prophylactic, RSV Respiratory syncytial virus, SSVR Södra sjukvårdsregionen, SÖSVR Sydöstra sjukvårdsregionen, $T L V$ Tandvårds- och läkemedelsförmånsverket, QALY quality-adjusted life year, $y$ years

${ }^{\text {a }}$ This price includes hospital stay which was accounted for in calculations

of 0.10 (assumed) for those RSV-hospitalized. Asthma and CHD-complications further decreased the utility, as shown in Table 1.

\section{Sensitivity analysis and scenario analysis}

One-way sensitivity analysis was used to test the robustness of the results for alterations in individual input data items by separately increasing/decreasing each variable by $\pm 50 \%$, except for the utilities, which generated a range of the ICER for each variable.

Probabilistic sensitivity analysis using Monte-Carlo simulation $[22,23]$ was used to investigate the uncertainty around the ICER, presented as an ICER scatter plot.

The effect on the ICER of shorter time horizons of the analysis; excluding the consequences of delayed heart surgery; excluding asthma and RSV-mortality; and using the mortality of the general population was investigated in scenario analyses.

\section{Results}

The results of incidence in different outcomes from the simulation model are shown in Fig. 2. Palivizumab had the greatest impact compared to the non-prophylaxis cohort in terms of hospitalizations. There was an increased incidence in other outcomes, but with less of a difference to prophylactically treated children with CHD.

\section{Cost-effectiveness}

The mean costs, effects, and ICER per infant in the base case scenario are shown in Table 2. The prophylaxis treatment incurred a cost of 3664 EUR per treated infant. By avoiding RSV-hospitalizations and morbidity associated with RSV infection as a result of prophylaxis, substantial savings mainly due to fewer days in the ICU and fewer days with ECMO were generated. The lower incidence of asthma and complications due to delayed surgery in the prophylaxis-treated cohort also generated savings. Over a lifetime, the prophylaxis was estimated to result in a cost-saving of 3833 EUR per CHD infant. In addition, the prophylaxis-treated cohort accumulated more life-years and higher quality of life than the nonprophylaxis cohort, resulting for the base case in a gain of 0.06 QALYs.

\section{Sensitivity analysis and scenario analysis}

Results from the one-way sensitivity analysis of the base case are shown in Table 3 . When changing the variable values by $\pm 50 \%$, respectively, the prophylaxis treatment arm remained dominant (lower costs and higher

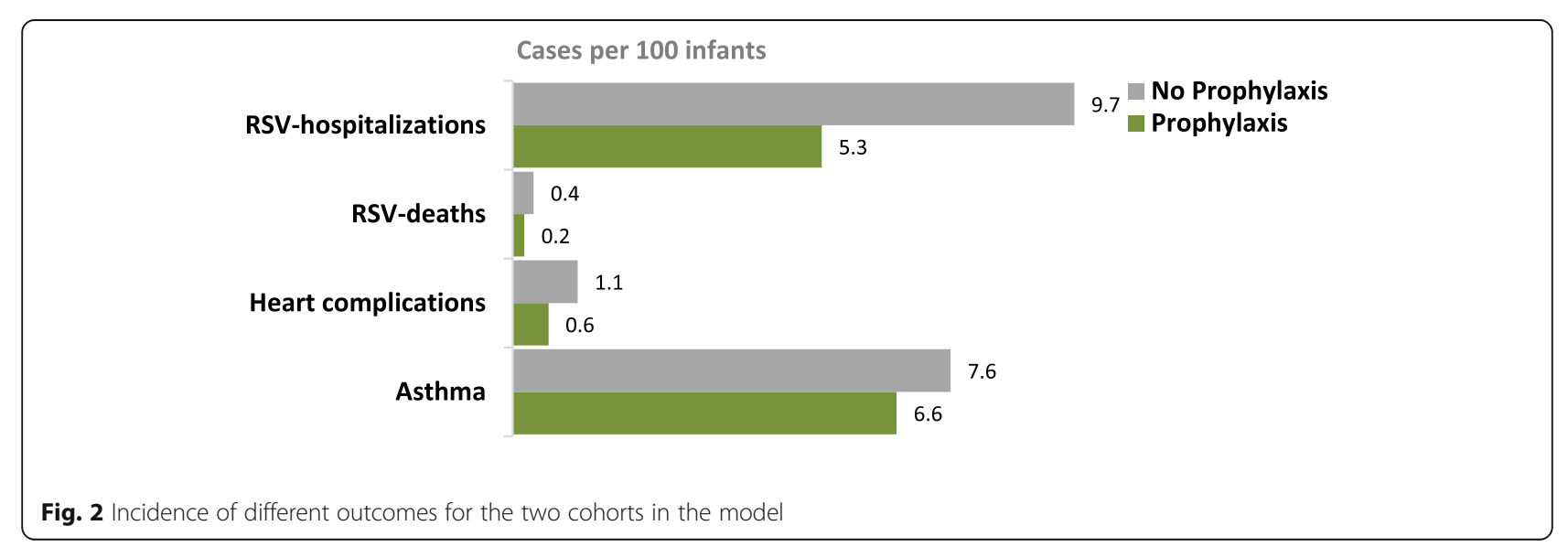


Table 2 Costs, effects and incremental cost-effectiveness ratios (ICER) for the base case scenario. Data indicate mean values per infant

\begin{tabular}{|c|c|c|c|}
\hline & Prophylaxis & No Prophylaxis & Difference \\
\hline Prophylaxis & 3664 EUR & 0 EUR & 3664 EUR \\
\hline RSV-hospitalizations & 5171 EUR & 10,315 EUR & -5145 EUR \\
\hline General & 499 EUR & 691 EUR & - 191 EUR \\
\hline ICU & 286 EUR & 1279 EUR & - 993 EUR \\
\hline Supplemental oxygen & 96 EUR & 349 EUR & -253 EUR \\
\hline Mechanical ventilation & 23 EUR & 188 EUR & -165 EUR \\
\hline CPAP & 400 EUR & 727 EUR & -327 EUR \\
\hline ECMO & 3744 EUR & 6806 EUR & - 3063 EUR \\
\hline Hotel nights & 55 EUR & 124 EUR & -69 EUR \\
\hline Productivity losses & 68 EUR & 152 EUR & -84 EUR \\
\hline Heart complications & 2544 EUR & 4626 EUR & -2082 EUR \\
\hline Asthma & 1470 EUR & 1739 EUR & - 270 EUR \\
\hline Total costs & 12,848 EUR & 16,681 EUR & -3833 EUR \\
\hline Total QALYs & 17.82 & 17.75 & 0.06 \\
\hline Total LY & 20.15 & 20.12 & 0.03 \\
\hline ICER (QALY) & & & DOMINANCE \\
\hline ICER (LYG) & & & DOMINANCE \\
\hline
\end{tabular}

CPAP Continuous positive airway pressure, ECMO Extracorporeal membrane oxygenation, ICER incremental cost-effectiveness ratio, ICU Intensive care unit, $L Y$ Life year, LYG Life year gained, Proph prophylactic, RSV Respiratory syncytial virus, $Q A L Y$ quality-adjusted life year, $y$ years

utilities) in all cases except when the HR for RSV hospitalization of children treated with prophylaxis was increased by $50 \%$. In that case, the ICER was 7875 EUR/ QALY which, with a high margin, still would be regarded as very cost-effective [46].

The results from the probabilistic sensitivity analysis (Fig. 3 in Appendix) showed that the probability of RSV-prophylaxis to be cost-saving compared to no prophylaxis was close to $100 \%$, given the joint uncertainty of the input data (Table 3 in Appendix).

In scenario analyses, a shorter time horizon of the analysis was shown to have the greatest impact on the costeffectiveness of RSV-prophylaxis (Table 4 in Appendix). The prophylactic treatment was however still dominant when the time horizon was set to only 1 year as opposed to lifetime in the base case. Excluding asthma and RSVmortality had a clear impact on QALYs but only minor effects on the costs, still leading to cost-savings and higher utility. If the effect of delayed heart surgeries due to RSV-hospitalization was removed from the model, the cost savings were lowered to 1751 EUR and the incremental QALYs to 0.05 . If using the mortality from the general population in the model instead of the adjusted mortality for CHD infants used in the base case, the cost-savings and utility of prophylaxis would be even greater.

\section{Discussion}

The cost-effectiveness for RSV-prophylaxis with palivizumab as compared to no prophylaxis among Swedish CHD-infants aged less than 1 year during RSV-season and with cardiac defects adherent to the current national guidelines of prophylaxis showed that RSV-prophylaxis was associated with not only improved health effects, but also cost-savings of 3833 EUR per infant. The analysis included hospitalization, delayed surgery, asthma, and death as well as cost associated with parental care due to a child being hospitalized for RSV.

RSV-prophylaxis was cost-effective in CHD-infants who are included in the prophylactic program in this present study. In addition to more commonly used cost-driving entities such as hospitalization and mechanical ventilation in the ICU, we included an effect of delayed surgery, parental productivity loss, and asthma. The results remained unaltered when the robustness was tested, and these characteristics were excluded from the analysis. There has been notable variance in included study characteristics, analytic models utilized, duration of RSV seasons assessed, primary outcome measures evaluated, and sensitivity analyses conducted along with other model assumptions in other studies on cost-effectiveness on palivizumab in children with CHD. Thus, comparing results can be difficult and the cost effectiveness may to some extent still be inconclusive $[21,26]$. Some of the earlier studies have evaluated short-term benefits, such as reducing hospitalizations and associated costs, while more recent studies have included long-term benefits such as asthma, QALYs, or life-years gained (LYG). Most of the studies performed in the highincome countries have shown that palivizumab in children with hemodynamically congenital heart disease is cost effective [16-19, 47, 48].

Congenital cardiac surgery performed during RSV infection is associated with a high risk of peri- and post-operative complications and mortality [9, 11]. These risks are of higher severity among the youngest patients and with more severe types of CHD. Thus, if a child is infected by RSV less than 6 weeks prior to heart surgery, this operation is often delayed. A delayed operation may however further increase the cardiac morbidity with increased cyanosis and/or heart failure. Previous cost-effectiveness studies of RSVprophylaxis for children with CHD have not included the impact of delayed surgery. We found the costeffective impact as well as health and quality of life factors in children with CHD were improved by RSVprophylaxis. 
Table 3 Results from one-way sensitivity analysis of the base case

\begin{tabular}{|c|c|c|c|c|c|c|}
\hline \multirow[b]{2}{*}{ Variable } & \multicolumn{3}{|l|}{ Value } & \multicolumn{3}{|c|}{ ICER (SEK/QALY) } \\
\hline & Low & Base case & High & Low & Base case & High \\
\hline Risk of RSV-hospitalization & $4.9 \%$ & $9.7 \%$ & $14.6 \%$ & Dominance & Dominance & Dominance \\
\hline HR RSV hospitalization (proph) & 0.28 & 0.55 & 0.83 & Dominance & Dominance & 7875 \\
\hline Death from RSV hospitalization & $1.9 \%$ & $3.7 \%$ & $5.6 \%$ & Dominance & Dominance & Dominance \\
\hline Proportion delayed surgeries due to RSV-hosp & $15.0 \%$ & $30.0 \%$ & $45.0 \%$ & Dominance & Dominance & Dominance \\
\hline Proportion general complication from delayed surgery & $20.0 \%$ & $40.0 \%$ & $60.0 \%$ & Dominance & Dominance & Dominance \\
\hline Death (compl., delayed surgery) & $0.5 \%$ & $1.0 \%$ & $1.5 \%$ & Dominance & Dominance & Dominance \\
\hline LOS, RSV hospitalization & 6.6 & 13.3 & 19.9 & Dominance & Dominance & Dominance \\
\hline LOS, RSV hospitalization (proph) & 5.4 & 10.8 & 16.2 & Dominance & Dominance & Dominance \\
\hline LOS, ICU & 3.7 & 7.3 & 11.0 & Dominance & Dominance & Dominance \\
\hline LOS, ICU (proph) & 1.5 & 3.0 & 4.5 & Dominance & Dominance & Dominance \\
\hline Days with suppl. Oxygen & 5.2 & 10.4 & 15.7 & Dominance & Dominance & Dominance \\
\hline Days with suppl. Oxygen (proph) & 2.6 & 5.2 & 7.9 & Dominance & Dominance & Dominance \\
\hline Days with mechanical ventilation & 2.8 & 5.6 & 8.4 & Dominance & Dominance & Dominance \\
\hline Days with mechanical ventilation (proph) & 0.6 & 1.2 & 1.9 & Dominance & Dominance & Dominance \\
\hline Days with ECMO & 4.1 & 8.2 & 12.3 & Dominance & Dominance & Dominance \\
\hline Days with ECMO (proph) & 4.1 & 8.2 & 12.3 & Dominance & Dominance & Dominance \\
\hline Days with CPAP & 1.8 & 3.5 & 5.3 & Dominance & Dominance & Dominance \\
\hline Days with CPAP (proph) & 1.8 & 3.5 & 5.3 & Dominance & Dominance & Dominance \\
\hline RSV hosp (cost per day) & 598 & 1197 & 1795 & Dominance & Dominance & Dominance \\
\hline ICU (cost per day) & 302 & 605 & 907 & Dominance & Dominance & Dominance \\
\hline Suppl. oxygen (cost per day) & 172 & 344 & 517 & Dominance & Dominance & Dominance \\
\hline Mechanical ventilation (cost per day) & 172 & 344 & 517 & Dominance & Dominance & Dominance \\
\hline ECMO (cost per day) & 4296 & 8592 & 12,888 & Dominance & Dominance & Dominance \\
\hline CPAP (cost per day) & 1071 & 2141 & 3212 & Dominance & Dominance & Dominance \\
\hline Hotel (cost per night) & 48 & 96 & 144 & Dominance & Dominance & Dominance \\
\hline Productivity loss (value per day) & 59 & 118 & 177 & Dominance & Dominance & Dominance \\
\hline Cost of prophylaxis, per infant & 1832 & 3664 & 5496 & Dominance & Dominance & Dominance \\
\hline Dose, Synagis & 8 & 15 & 23 & Dominance & Dominance & Dominance \\
\hline Cost per mg, Synagis & 4 & 8 & 12 & Dominance & Dominance & Dominance \\
\hline Weight factor, OWSA & 0.50 & 1.00 & 1.50 & Dominance & Dominance & Dominance \\
\hline Annual cost asthma & 720 & 1440 & 2160 & Dominance & Dominance & Dominance \\
\hline Cost of general CHD-complication (annual) & 10,753 & 21,506 & 32,260 & Dominance & Dominance & Dominance \\
\hline Base utility & 0.79 & 0.89 & 1.00 & Dominance & Dominance & Dominance \\
\hline Utility decrement of RSV hospitalization & $5.0 \%$ & $10.0 \%$ & $15.0 \%$ & Dominance & Dominance & Dominance \\
\hline Asthma utility & $65.0 \%$ & $79.0 \%$ & $100.0 \%$ & Dominance & Dominance & Dominance \\
\hline Utility decrement of heart complication & 0.05 & 0.10 & 0.15 & Dominance & Dominance & Dominance \\
\hline Discount rate, costs & $0.0 \%$ & $3.0 \%$ & $5.0 \%$ & Dominance & Dominance & Dominance \\
\hline Discount rate, effects & $0.0 \%$ & $3.0 \%$ & $5.0 \%$ & Dominance & Dominance & Dominance \\
\hline
\end{tabular}

CPAP Continuous positive airway pressure, ECMO Extracorporeal membrane oxygenation, ICU Intensive care unit, HR hazard ratio, LOS Length of stay, OWSA Oneway sensitivity analyses, Proph prophylactic, RSV Respiratory syncytial virus

The risk of RSV-hospitalization and the treatment effect of RSV-prophylaxis among CHD-infants in our study were retrieved from a large randomized control trial [13]. The impact of these variables was tested in sensitivity analyses in the present study. The results showed that even if the risk of RSV-hospitalization or 
the effect of RSV-prophylaxis were very low (half of the base case value), the ICERs were still well below the threshold of being very cost effective given the high disease severity of this patient population.

As a long-term complication to RSV infection, asthma has been included in previous studies of costeffectiveness analyses covering RSV-prophylaxis with palivizumab in sensitive children [16, 17, 47]. Specific data of the risk of asthma following RSV among children with CHD is lacking. The risk for asthma following RSV infection in otherwise healthy Swedish infants was used in the analysis [28]. However, CHD infants may have a different risk of asthma. A scenario analysis was performed to rule out this risk, showing that even if asthma would be completely excluded from the analysis, palivizumab as RSV-prophylaxis would still result in costsavings. One previous study in premature infants has suggested that prophylactic treatment with palivizumab may reduce subsequent recurrent wheezing [49]. The effect on asthma and wheezing following RSV infection on children with CHD with palivizumab is not known.

Productivity costs due to temporary parental allowance and productive loss was included in the analysis but had a minor impact on the outcome. Swedish parents are provided parental benefit when their child is sick at home or hospitalized. Given the lack of robust evidence regarding the extent of parental care or short-term absence to take care of the child when hospitalized, our estimates should be interpreted with caution. Some other studies have included costs related to parental care of the child with similar results. However, these studies are performed in countries with different socioeconomic systems and the only study in Scandinavia did not include this as well as several other cost components in the analysis [17, 19, 20, 47].

The results from the analysis in this study may be underestimating the cost-effectiveness of RSVprophylaxis, as only the effect on very severe RSVinfections leading to hospitalization was included. Costs associated with outpatient RSV bronchiolitis and treatment is difficult to ascertain but may have influenced our results. Furthermore, a decreased quality-of-life while waiting for a delayed heart surgery was not included in the calculation which if included would have contributed to higher QALY gains. Palivizumab is injected monthly intramuscularly by pediatric nurses at each pediatric cardiac center at a university- or county hospital. Costs associated with travel for clinic visits, injections, or nurse consultations have not been included in the analysis. Further, when the sterile seal of a vial is broken there may be some surplus of the drug not being used, and should maybe have been included in the costs. In our hospitals (Crown Princess Victoria Children's Hospital University Hospital and Sahlgrenska University Hospital) this is a minor issue, as nurses often collect all children for prophylactic treatment timely to reduce the costs. Although some of the above mentioned issues have been accounted for in some other studies, an inclusion of these data is not likely to alter our results $[17,19]$.

Omitting or delaying palivizumab prophylaxis has been linked to increased rates of re-hospitalization. A previous Swedish study has found a delay in the start of prophylactic treatment among almost half of the children in the prophylactic program [43]. The results from our study indicate that timing and correct diagnosis of $\mathrm{CHD}$ is essential to benefit from cost-effectiveness of prophylactic treatment.

The cost-effectiveness shown in our study is based on the national guidelines on prophylactic treatment with palivizumab for children with CHD in Sweden [24] but the cost of the drug is a major concern. Our study used current Swedish guidelines in the analysis, which includes prophylactic treatment to the most severe types of CHD. Strict patient selection criteria are essential and use of palivizumab in a broader population than recommended in the guidelines is not justified by our study. In a recent Swedish study, the risk of RSV hospitalization for less severe cardiac defects was equal to that of severely ill children [36]. A cost-effectiveness study for that patient group would be the next logical step.

Delayed heart surgery is difficult to quantify due to limited available data. Data on risk of RSV-hospitalization might be different for Sweden compared to the multicentered study used in our analysis, which may further limit the study. Other risk factors for RSV infection, such as premature birth, prenatal exposure to maternal smoking and exposure to environmental tobacco smoke, lack of breastfeeding, living in crowded households, low birth weight, day care attendance among older siblings in the household, and increased risk for nosocomial infections have not been considered in this study, which may limit the overall aspects of RSV-prophylatic treatement [5052]. Prophylactic treatment can therefor include information to parents and healthcare staff of the risk for severe viral infection in children with all types of $\mathrm{CHD}$, and with special attention to the risk of nosocomial infection. The effect of this precaution is difficult to evaluate but may also reduce hospitalization rates.

\section{Conclusion}

This study confirms that Swedish guidelines on RSVprophylaxis with severe CHD in infants less than 1 year of age is cost effective. Avoiding delayed heart surgeries is an important aspect of the prophylaxis' benefits and should be taken into consideration. However, further studies on the frequency and costs of delayed heart surgery are also needed to gain a better understanding of the impact RSV on society. 


\section{Appendix}

Table 4 The variables used in the probabilistic sensitivity analysis, with their associated uncertainty and distributions

\begin{tabular}{|c|c|c|c|}
\hline Variable & Mean value & Standard error (SE) & Distribution \\
\hline Risk of RSV-hospitalization & $9.7 \%$ & 0.010 & beta \\
\hline HR RSV hospitalization (proph) & 0.55 & 0.055 & lognormal \\
\hline Death from RSV hospitalization & $3.7 \%$ & 0.004 & beta \\
\hline Proportion delayed surgeries due to RSV-hosp & $30.0 \%$ & 0.030 & beta \\
\hline Proportion general complication from delayed surgery & $40.0 \%$ & 0.040 & beta \\
\hline Death (compl., delayed surgery) & $1.0 \%$ & 0.001 & beta \\
\hline LOS, RSV hospitalization & 13.27 & 1.33 & gamma \\
\hline LOS, RSV hospitalization (proph) & 10.79 & 1.08 & gamma \\
\hline LOS, ICU & 7.32 & 0.73 & gamma \\
\hline LOS, ICU (proph) & 2.97 & 0.30 & gamma \\
\hline Days with suppl. Oxygen & 10.44 & 1.04 & gamma \\
\hline Days with suppl. Oxygen (proph) & 5.24 & 0.52 & gamma \\
\hline Days with mechanical ventilation & 5.62 & 0.56 & gamma \\
\hline Days with mechanical ventilation (proph) & 1.24 & 0.12 & gamma \\
\hline Days with ECMO & 8.17 & 0.82 & gamma \\
\hline Days with ECMO (proph) & 8.17 & 0.82 & gamma \\
\hline Days with CPAP & 3.50 & 0.35 & gamma \\
\hline Days with CPAP (proph) & 3.50 & 0.35 & gamma \\
\hline RSV hosp (cost per day) & 1197 EUR & 120 & gamma \\
\hline ICU (cost per day) & 605 EUR $^{1}$ & 60 & gamma \\
\hline Suppl. oxygen (cost per day) & 344 EUR & 34 & gamma \\
\hline Mechanical ventilation (cost per day) & 344 EUR & 34 & gamma \\
\hline ECMO (cost per day) & 8592 EUR & 859 & gamma \\
\hline CPAP (cost per day) & 2141 EUR & 214 & gamma \\
\hline first injection (kg) & 5.00 & 0.50 & normal \\
\hline second injection (kg) & 5.40 & 0.54 & normal \\
\hline third injection $(\mathrm{kg})$ & 5.80 & 0.58 & normal \\
\hline fourth injection (kg) & 6.40 & 0.64 & normal \\
\hline fifth injection (kg) & 7.00 & 0.70 & normal \\
\hline Annual cost asthma & 1440 EUR & 144 & gamma \\
\hline Cost of general CHD-complication (annual) & 21,506 EUR & 2151 & gamma \\
\hline Base utility & 0.89 & 0.089 & beta \\
\hline Utility decrement of RSV hosp & 0.10 & 0.010 & beta \\
\hline Asthma utility & 0,79 & 0,079 & beta \\
\hline Utility decrement of heart complication & 0,10 & 0,010 & beta \\
\hline
\end{tabular}


Table 5 Costs, effects and incremental cost-effectiveness ratios (ICER) for different scenarios. Data are expressed as mean value per infant

\begin{tabular}{|c|c|c|c|c|c|c|}
\hline \multirow[t]{2}{*}{ Scenario } & & \multirow[t]{2}{*}{ Costs } & \multirow[t]{2}{*}{ QALYS } & \multicolumn{2}{|l|}{ Incremental } & \multirow[t]{2}{*}{ ICER } \\
\hline & & & & Costs & QALYS & \\
\hline \multirow[t]{2}{*}{ Base case } & Prophylaxis & 12,848 EUR & 17.82 & -3833 EUR & 0.06 & Dominance \\
\hline & No Prophylaxis & 16,681 EUR & 17.75 & & & \\
\hline \multirow[t]{2}{*}{ Time horizon = 1y } & Prophylaxis & 8834 EUR & 0.88 & - 1481 EUR & 0.01 & Dominance \\
\hline & No Prophylaxis & 10,315 EUR & 0.88 & & & \\
\hline \multirow[t]{2}{*}{ Time horizon $=5 y$} & Prophylaxis & 9341 EUR & 3.76 & -1868 EUR & 0.01 & Dominance \\
\hline & No Prophylaxis & 11,209 EUR & 3.74 & & & \\
\hline \multirow[t]{2}{*}{ Time horizon $=10 \mathrm{y}$} & Prophylaxis & 9964 EUR & 6.84 & -2292 EUR & 0.02 & Dominance \\
\hline & No Prophylaxis & 12,255 EUR & 6.81 & & & \\
\hline \multirow[t]{2}{*}{ No asthma } & Prophylaxis & 11,378 EUR & 17.92 & - 3563 EUR & 0.04 & Dominance \\
\hline & No Prophylaxis & 14,941 EUR & 17.88 & & & \\
\hline \multirow[t]{2}{*}{ No RSV-death } & Prophylaxis & 12,962 EUR & 17.85 & - 3925 EUR & 0.03 & Dominance \\
\hline & No Prophylaxis & 16,887 EUR & 17.82 & & & \\
\hline \multirow[t]{2}{*}{ No RSV-death, no asthma } & Prophylaxis & 11,477 EUR & 17.95 & -3643 EUR & 0.01 & Dominance \\
\hline & No Prophylaxis & 15,120 EUR & 17.94 & & & \\
\hline \multirow[t]{2}{*}{ No delayed heart surgeries } & Prophylaxis & 10,304 EUR & 17.83 & -1751 EUR & 0.05 & Dominance \\
\hline & No Prophylaxis & 12,055 EUR & 17.78 & & & \\
\hline \multirow[t]{2}{*}{ Mortality = general population } & Prophylaxis & 15,337 EUR & 27.30 & -5137 EUR & 0.10 & Dominance \\
\hline & No Prophylaxis & 20,474 EUR & 27.21 & & & \\
\hline \multirow[t]{2}{*}{ No productivity loss } & Prophylaxis & 10,236 EUR & 17.82 & -1667 EUR & 0.06 & Dominance \\
\hline & No Prophylaxis & 11,903 EUR & 17.75 & & & \\
\hline \multirow[t]{2}{*}{ Productivity loss of both parents } & Prophylaxis & 12,916 EUR & 17.82 & -3916 EUR & 0.06 & Dominance \\
\hline & No Prophylaxis & 16,832 EUR & 17.75 & & & \\
\hline
\end{tabular}

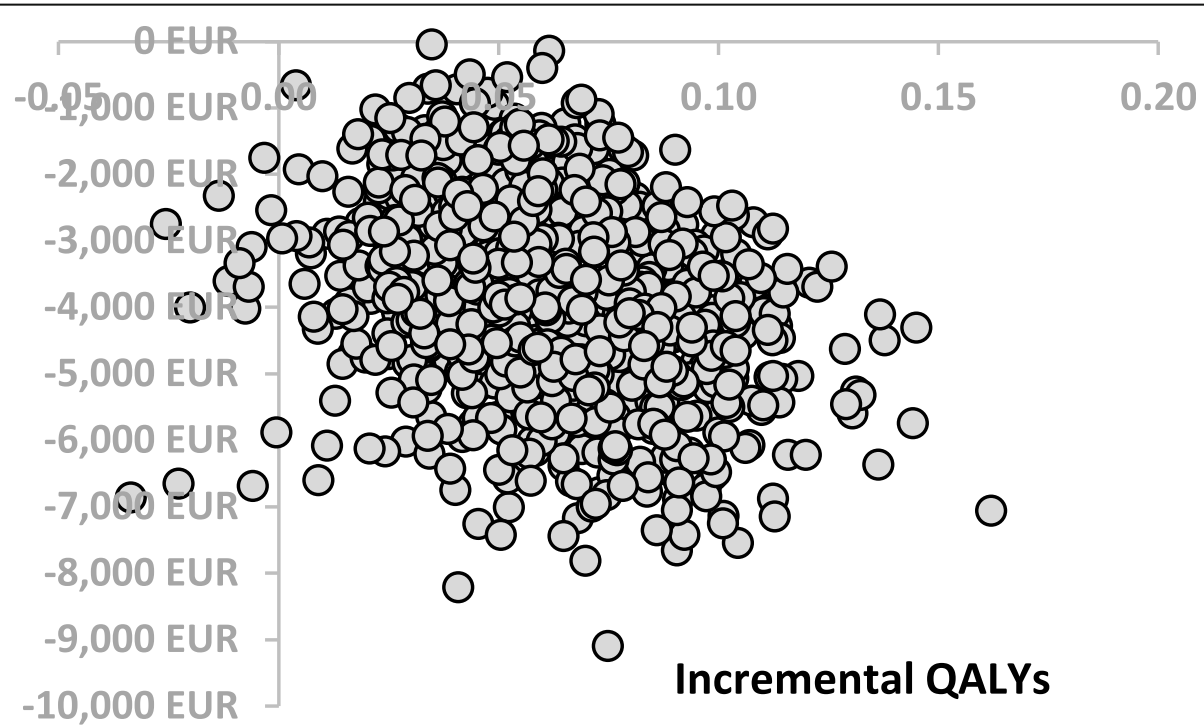

Fig. 3 ICER scatter plot from the probabilistic sensitivity analysis 


\section{Supplementary information}

Supplementary information accompanies this paper at https://doi.org/10. 1186/s40949-020-00036-w.

\section{Additional file 1.}

\section{Abbreviations}

CHD: congenital heart disease; CPAP: continuous positive airway pressure: ECMO: extracorporeal membrane oxygenation; ICER: incremental costeffectiveness ratios; ICU: intensive care; LRTI: lower respiratory tract infections; PICU: pediatric intensive care unit; QALYs: quality-adjusted life-years; RSV: Respiratory syncytial virus

\section{Acknowledgements}

EF received research-time by funding from Region Östergötland (ALF) and the Medical Research Council of Southeast Sweden (FORSS).

The authors wish to thank Rongrong Zhang, formerly an AbbVie employee, for valuable input to the study design and initial data analysis."

\section{Financial disclosure}

The design, study conduct, and financial support for the study were provided by AbbVie. AbbVie participated in the study design, data analysis, interpretation of results, review, and approval of the publication. The authors determined the final content. No payments were made to the authors for writing this publication. Open access funding provided by Umea University.

\section{Authors' contributions}

AbbVie participated in the study design, retrieval of data, data analysis, review and approval of the publication. The authors interpreted the results and determined the final content. Dr. Estelle Naumburg had primary responsibility for study, protocol development, and writing the manuscript. Martin Eriksson had the performed the health economic analysis with input from Dr. Jonas Söderholm and contributed to the writing of the manuscript. Dr. Eva Fernlund and Jan Sunnegardh participated by acquisition of county council price list and clinical data, in the analytical framework for the study and contributed to the writing of the manuscript.

\section{Availability of data and materials}

The data that support the findings of this study are available in/from sources referred to in the manuscript, reference-list and Table 1.

\section{Ethics approval and consent to participate} Not applicable.

\section{Consent for publication}

Not applicable.

\section{Competing interests}

EF, JaS, and EN have nothing to disclose. ME and JoS are employed by AbbVie and may hold AbbVie stocks or stock options.

\section{Author details}

${ }^{1}$ Department of Paediatrics, and Department of Biomedical and Clinical Sciences, Crown Princess Victoria Children's Hospital, Linköping University Hospital, Linköping University, Linköping, Sweden. ${ }^{2}$ AbbVie AB, Stockholm, Sweden. ${ }^{3}$ Division of Clinical Microbiology, Department of Laboratory Medicine, Karolinska Institutet at Karolinska University Hospital Huddinge, Stockholm, Sweden. ${ }^{4}$ Department of Cardiology at the Queen Silvis Children's Hospital, Sahlgrenska University Hospital, Gothenburg, Sweden. ${ }^{5}$ Department of Clinical Science, Paediatrics, Umeå University, Umeå, Sweden.

Received: 12 May 2020 Accepted: 2 August 2020

Published online: 01 October 2020

\section{References}

1. Aujard $Y$, Fauroux B. Risk factors for severe respiratory syncytial virus infection in infants. Respir Med. 2002;96(Suppl B):S9-14.

2. Law BJ, Carbonell-Estrany $X$, Simoes EA. An update on respiratory syncytial virus epidemiology: a developed country perspective. Respir Med. 2002; 96(Suppl B):S1-7.
3. Fixler DE. Respiratory syncytial virus infection in children with congenital heart disease: a review. Pediatr Cardiol. 1996;17(3):163-8.

4. Kristensen $\mathrm{K}$, et al. Chronic diseases, chromosomal abnormalities, and congenital malformations as risk factors for respiratory syncytial virus hospitalization: a population-based cohort study. Clin Infect Dis. 2012;54(6): 810-7.

5. Jackson DJ, et al. Wheezing rhinovirus illnesses in early life predict asthma development in high-risk children. Am J Respir Crit Care Med. 2008;178(7): $667-72$

6. Mohapatra SS, Boyapalle S. Epidemiologic, experimental, and clinical links between respiratory syncytial virus infection and asthma. Clin Microbiol Rev. 2008;21(3):495-504.

7. Sigurs $N$, et al. Severe respiratory syncytial virus bronchiolitis in infancy and asthma and allergy at age 13. Am J Respir Crit Care Med. 2005;171(2):13741.

8. Henderson J, et al. Hospitalization for RSV bronchiolitis before 12 months of age and subsequent asthma, atopy and wheeze: a longitudinal birth cohort study. Pediatr Allergy Immunol. 2005;16(5):386-92.

9. Khongphatthanayothin A, et al. Impact of respiratory syncytial virus infection on surgery for congenital heart disease: postoperative course and outcome. Crit Care Med. 1999:27(9):1974-81.

10. Moynihan K, et al. Impact of viral respiratory pathogens on outcomes after pediatric cardiac surgery. Pediatr Crit Care Med. 2017;18(3):219-27.

11. Nicolas RT, et al. Early outcome after Glenn shunt and Fontan palliation and the impact of operation during viral respiratory season: analysis of a 19-year multi-institutional experience. Ann Thorac Surg. 2005;79(2):613-7 discussion 617.

12. Andabaka, T., et al., Monoclonal antibody for reducing the risk of respiratory syncytial virus infection in children. Cochrane Database Syst Rev, 2013, Issue 4. Art. No.: CD006602. DOl: https://doi.org/10.1002/14651858.CD006602. pub4

13. Feltes TF, et al. Palivizumab prophylaxis reduces hospitalization due to respiratory syncytial virus in young children with hemodynamically significant congenital heart disease. J Pediatr. 2003:143(4):532-40.

14. Resch B. Respiratory syncytial virus infection in high-risk infants - an update on Palivizumab prophylaxis. Open Microbiol J. 2014;8:71-7.

15. Lofland $\mathrm{JH}$, et al. Palivizumab for respiratory syncytial virus prophylaxis in high-risk infants: a cost-effectiveness analysis. Clin Ther. 2000;22(11):1357-69.

16. Bentley $A$, et al. A cost-effectiveness analysis of respiratory syncytial virus (RSV) prophylaxis in infants in the United Kingdom. Health Econ Rev. 2013; 3(1):18

17. Nuijten M, Lebmeier M, Wittenberg W. Cost effectiveness of palivizumab for RSV prevention in high-risk children in the Netherlands. J Med Econ. 2009; 12(4):291-300.

18. Resch B, et al. Cost-effectiveness of palivizumab for respiratory syncytial virus infection in high-risk children, based on long-term epidemiologic data from Austria. Pediatr Infect Dis J. 2012;31(1):e1-8.

19. Harris KC, et al. Economic evaluation of palivizumab in children with congenital heart disease: a Canadian perspective. Can J Cardiol. 2011;27(4): 523 e11-5.

20. Meberg A, Bruu AL. Respiratory syncytial virus infections in congenital heart defects--hospitalizations and costs. Acta Paediatr. 2006;95(4):404-6.

21. Hussman JM, Lanctot $\mathrm{KL}$, Paes $B$. The cost effectiveness of palivizumab in congenital heart disease: a review of the current evidence. J Med Econ. 2013:16(1):115-24

22. Drummond, M.F., et al., Methods for the Economic Evaluation of Health Care Programmes. 4th ed. 2015: Oxford University.

23. Neovius K, et al. Cost-effectiveness analysis of palivizumab as respiratory syncytial virus prophylaxis in preterm infants in Sweden. Acta Paediatr. 2011; 100(10):1306-14.

24. Naumburg, E.F., E. Sunnegårdh, J. Lundell, B. Nationell rekommendation för profylax med Palivizumab mot RSV-infektion hos barn med hjärtsjukdom. 2013

25. TLV, Tandvård- och läkemedels-förmånsverkets allmänna råd. 2015.

26. Wang, D., S. Bayliss, and C. Meads, Palivizumab for immunoprophylaxis of respiratory syncytial virus (RSV) bronchiolitis in high-risk infants and young children: a systematic review and additional economic modelling of subgroup analyses. Health Technol Assess, 2011. 15(5): iii-iv, 1-124.

27. Khan JY, et al. Role of ECMO in the treatment of respiratory syncytial virus bronchiolitis: a collaborative report. Arch Dis Child Fetal Neonatal Ed. 1995: 73(2):F91-4. 
28. Sigurs $\mathrm{N}$, et al. Asthma and allergy patterns over 18 years after severe RSV bronchiolitis in the first year of life. Thorax. 2010;65(12):1045-52.

29. Sigurs $\mathrm{N}$, et al. Asthma and immunoglobulin $\mathrm{E}$ antibodies after respiratory syncytial virus bronchiolitis: a prospective cohort study with matched controls. Pediatrics. 1995;95(4):500-5.

30. Geskey JM, Cyran SE. Managing the morbidity associated with respiratory viral infections in children with congenital heart disease. Int J Pediatr. 2012; 2012:646780. https://doi.org/10.1155/2012/646780.

31. Geskey JM, Thomas NJ, Brummel GL. Palivizumab: a review of its use in the protection of high risk infants against respiratory syncytial virus (RSV). Biologics. 2007;1(1):33-43.

32. Greenough A. Role of ventilation in RSV disease: CPAP, ventilation, HFO, ECMO. Paediatr Respir Rev. 2009;10(Suppl 1):26-8.

33. SSVR, Regionala priser och ersättningar för Södra sjukvårdsregionen 2019 Södra sjukvårdsregionen. 2019.

34. SÖSVR, Priser och ersättningar för Sydöstra sjukvårdsregionen 2019. 2019.

35. Statistics Sweden. Sammanräknad förvärvsinkomst för boende i Sverige hela året efter region, kön, ålder och inkomstklass. År 1999-2018. 2018 [cited 2019 19 December]; Available from: http://www.scb.se/hitta-statistik/statistik-efteramne/arbetsmarknad/loner-och-arbetskostnader/konjunkturstatistik-lonerfor-statlig-sektor-kls/pong/publikationer/konjunkturstatistik-loner-for-statligsektor-oktober-2016/.

36. Granbom E, Fernlund E, Sunnegårdh J, Lundell B, Naumburg E. Respiratory Tract Infection and Risk of Hospitalization in Children with Congenital Heart Defects During Season and Off-Season: A Swedish National Study. Pediatr Cardiol. 2016;37(6):1098-105.

37. Greenough A, et al. Health care utilisation of prematurely born, preschool children related to hospitalisation for RSV infection. Arch Dis Child. 2004; 89(7):673-8.

38. Chiou CF, et al. Development of the multi-attribute pediatric asthma health outcome measure (PAHOM). Int J Qual Health Care. 2005;17(1):23-30.

39. Tandvårds- och läkemedelsförmånsverket, Ändring i Tandvårds- och läkemedelsförmånsverkets allmänna råd (TLVAR 2003:2) om ekonomiska utvärderingar. 2017.

40. Mandalenakis Z, et al. Survivorship in children and young adults with congenital heart disease in Sweden. JAMA Intern Med. 2017;177(2):224-30

41. Wren C, O'Sullivan JJ. Survival with congenital heart disease and need for follow up in adult life. Heart. 2001;85(4):438-43.

42. Gurvitz $M$, et al. Emerging research directions in adult congenital heart disease: a report from an NHLBI/ACHA working group. J Am Coll Cardiol. 2016;67(16):1956-64.

43. Granbom E, et al. Evaluating national guidelines for the prophylactic treatment of respiratory syncytial virus in children with congenital heart disease. Acta Paediatr. 2014;103(8):840-5.

44. Arnlind $\mathrm{MH}$, et al. The relationship between pharmaceutical costs, disease severity, and health-related quality of life in asthmatics in Swedish primary care. J Asthma. 2006;43(8):585-91.

45. Hederos CA, Janson S, Hedlin G. Six-year follow-up of an intervention to improve the management of preschool children with asthma. Acta Paediatr. 2009;98(12):1939-44.

46. Socialstyrelsen. National Board of Health and Welfare 2016; Available from: www.socialstyrelsen.se.

47. Nuijten M, Lebmeier M, Wittenberg W. Cost effectiveness of palivizumab in children with congenital heart disease in Germany. J Med Econ. 2009;12(4): 301-8.

48. Nuijten MJ, Wittenberg W. Cost effectiveness of palivizumab in Spain: an analysis using observational data. Eur J Health Econ. 2010;11(1):105-15.

49. Simoes EA, et al. Palivizumab prophylaxis, respiratory syncytial virus, and subsequent recurrent wheezing. J Pediatr. 2007;151(1):34-42 42 e1.

50. Thorburn K. Pre-existing disease is associated with a significantly higher risk of death in severe respiratory syncytial virus infection. Arch Dis Child. 2009; 94(2):99-103.

51. Groothuis JR, Hoopes JM, Hemming VG. Prevention of serious respiratory syncytial virus-related illness. II: Immunoprophylaxis. Adv Ther. 2011;28(2): 110-25.

52. Groothuis JR, Hoopes JM, Jessie VG. Prevention of serious respiratory syncytial virus-related illness. I: disease pathogenesis and early attempts at prevention. Adv Ther. 2011;28(2):91-109.

\section{Publisher's Note}

Springer Nature remains neutral with regard to jurisdictional claims in published maps and institutional affiliations.

\section{Ready to submit your research? Choose BMC and benefit from:}

- fast, convenient online submission

- thorough peer review by experienced researchers in your field

- rapid publication on acceptance

- support for research data, including large and complex data types

- gold Open Access which fosters wider collaboration and increased citations

- maximum visibility for your research: over $100 \mathrm{M}$ website views per year

At BMC, research is always in progress.

Learn more biomedcentral.com/submissions 